\title{
Eddy Current Transducer Dedicated for Sigma Phase Evaluation in Duplex Stainless Steel
}

\author{
Grzegorz Psuj, ${ }^{1}$ Tomasz Chady, ${ }^{1}$ and Cesar Giron Camerini ${ }^{2}$ \\ ${ }^{1}$ Department of Electrical and Computer Engineering, Faculty of Electrical Engineering, West Pomeranian University of Technology, \\ al. Piastow 17, 70-310 Szczecin, Poland \\ ${ }^{2}$ Laboratory of Nondestructive Testing, Corrosion and Welding, Department of Metallurgical and Materials Engineering, \\ Federal University of Rio de Janeiro, 21941-596 Rio de Janeiro, RJ, Brazil
}

Correspondence should be addressed to Tomasz Chady, tchady@zut.edu.pl

Received 3 December 2011; Accepted 6 February 2012

Academic Editor: B. P. C. Rao

Copyright ( 2012 Grzegorz Psuj et al. This is an open access article distributed under the Creative Commons Attribution License, which permits unrestricted use, distribution, and reproduction in any medium, provided the original work is properly cited.

The paper describes a new transducer dedicated for evaluation of a duplex stainless steel (DSS). Different phases which exist in DSS have influence on mechanical as well as on electrical properties. Therefore, an eddy current transducer was utilized. In order to achieve high sensitivity, a differential type of the transducer was selected. The performance of the transducer was verified by utilizing the samples which had a different amount of sigma phase.

\section{Introduction}

The duplex stainless steel (DSS) has been widely used in various industries, mainly because of good combination of mechanical properties and high corrosion resistance presented in this material $[1,2]$. The DSS properties are determined by the presence of two phases in microstructure having very different physical properties: ferrite $(\delta)$ and austenite $(\gamma)$. The austenite presents high electric conductivity and low magnetic permeability, while the ferrite presents low electric conductivity and high magnetic permeability. The best properties of DSS can be achieved when the phases $\delta$ and $\gamma$ are in equal proportions. In many cases production techniques of DSS pipes involve welding operation, which may lead to microstructural changes in the base metal and heat-affected zone (HAZ). Exposition to temperatures ranging from $300^{\circ} \mathrm{C}$ to $1000^{\circ} \mathrm{C}$ can cause changes of balance of the phases and/or precipitation of deleterious phases. The most harmful of the deleterious phases that can be originated in the material microstructure is sigma $(\sigma)$ phase. It presents higher than other phases volumetric fraction. Its precipitation causes chromium depletion in the adjacent regions, impairing dramatically mechanical and corrosion properties of the material [1-4].

The presence of $\sigma$ phase also causes changes of the electromagnetic properties of DSS. The ferrite is ferromag- netic while austenite and sigma phase are paramagnetic. Thus, an increase of the sigma phase and the resulting decrease of the ferrite phase volumetric fraction render the material behavior more paramagnetic [5]. This phenomena motivates to use an eddy current testing (ECT) method for the detection of material degradation caused by an increased presence of the sigma phase.

\section{Eddy Current Transducer and Measuring System}

In the preliminary experiments various configurations of the transducers were considered and tested. In order to distinguish small differences of the electric parameters, the transducer operating in a differential mode was selected. The transducer presented in this paper was build using an $\mathrm{H}$-shape ferrite core. Such shape of the ferrite allows to achieve higher density of the flux inside the material. Threedimensional model of the transducer and a cross-section view with dimensions is shown in Figure 1. Photos of the transducer are shown in Figure 2.

The transducer has a single excitation coil and two pickup coils. The main pick-up coil works in the neighborhood of a tested material having different amount of $\sigma$ phase. In the same time the reference pick-up coil is in the vicinity 


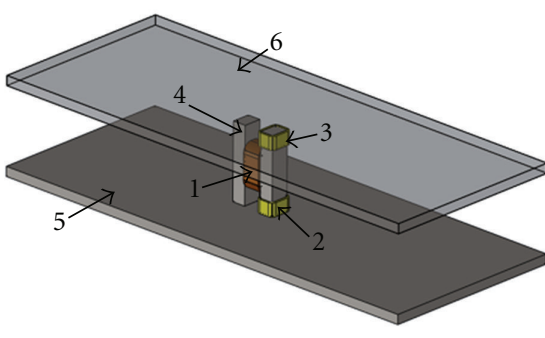

(a)

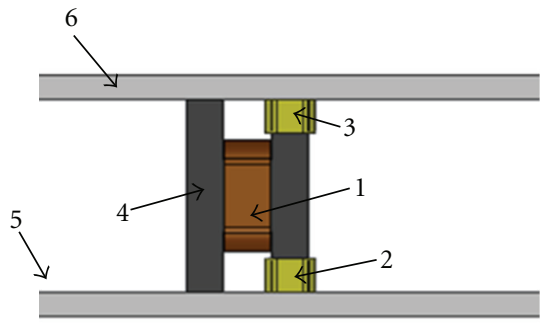

(b)

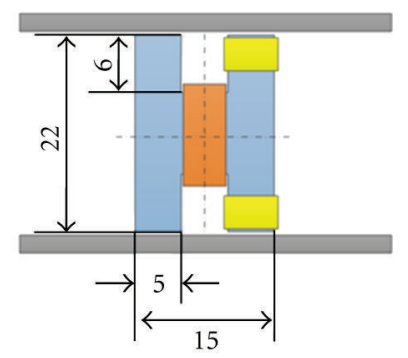

(c)

Figure 1: Views of the transducer: (a) three-dimensional view, (b) cross-section view, (c) view with dimensions (all given in mm); 1: excitation coil, 2: main section pick-up coil, 3: reference section pick-up coil; 4: ferrite core; 5: testing sample; 6: reference sample.

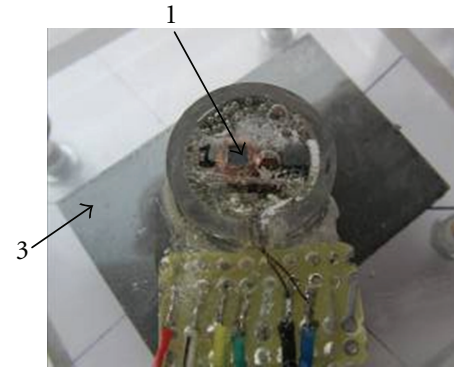

(a)

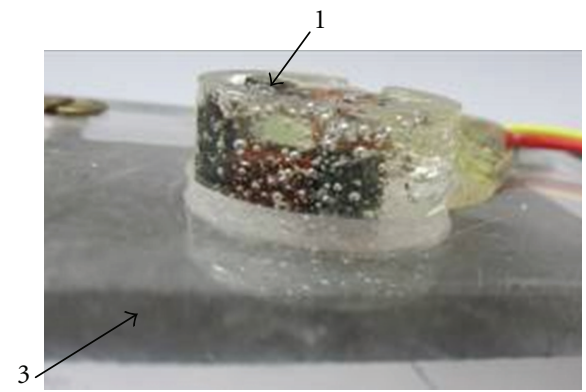

(b)

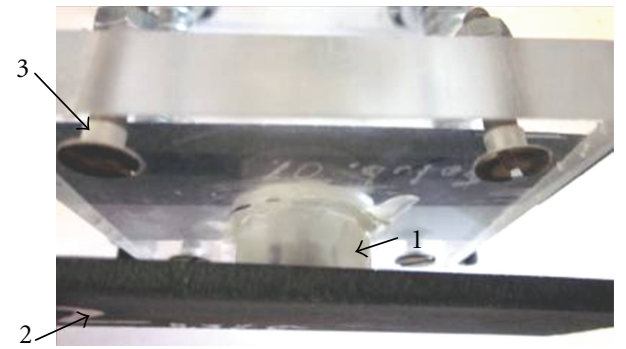

(c)

Figure 2: Photos of the transducer: (a) bottom view, (b) side view, (c) transducers over testing sample; 1: transducer, 2: testing sample, 3: reference sample.

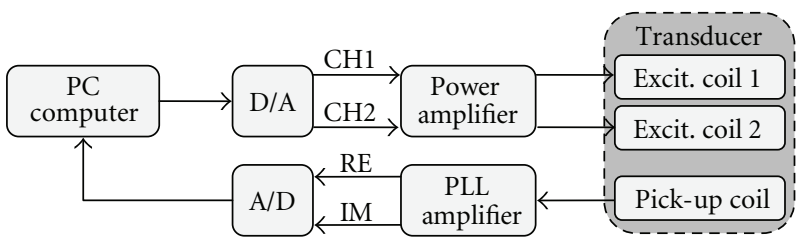

(a)

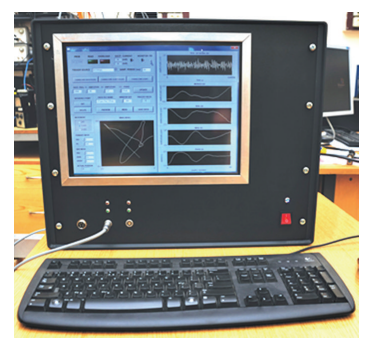

(b)

Figure 3: Block scheme (a) and photo (b) of the measuring system.

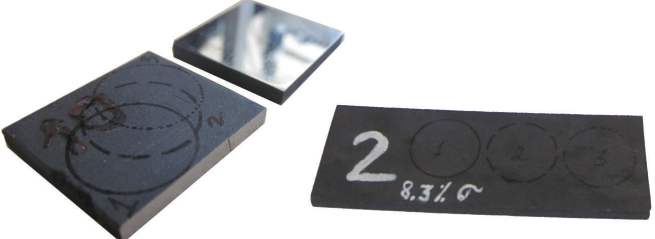

(a)

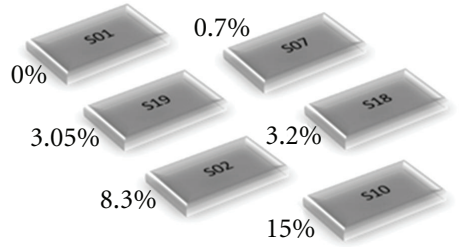

(b)

FIGURE 4: Testing DSS samples containing different amount of $\sigma$ phase: (a) photo of the samples, (b) view of the samples.

of the sample without $\sigma$ phase. The excitation coil is driven by power amplifiers. Pick-up coils of both sections are connected differentially so in the case of testing material without $\sigma$ phase the measured signal is close to zero. The $\sigma$ phase presence is causing the nonzero differential output voltage. However, the amplitude of the output voltage is relatively low (a few millivolts). Therefore, a lock-in amplifier that is commonly used to detect and measure very small AC signals [6] was utilized. The block scheme of the measuring system is presented in Figure 3. The system enables to carry 

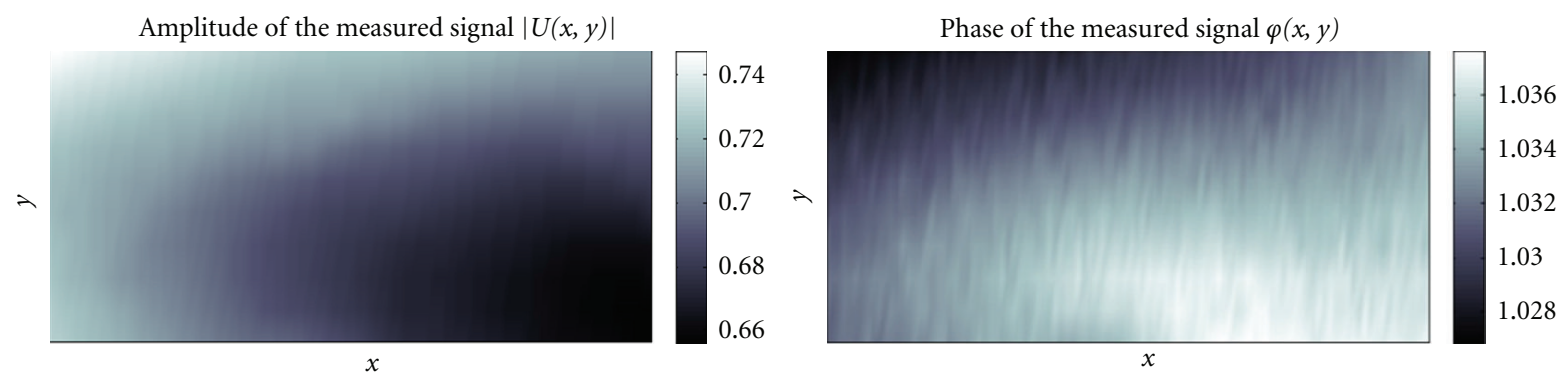

(a)
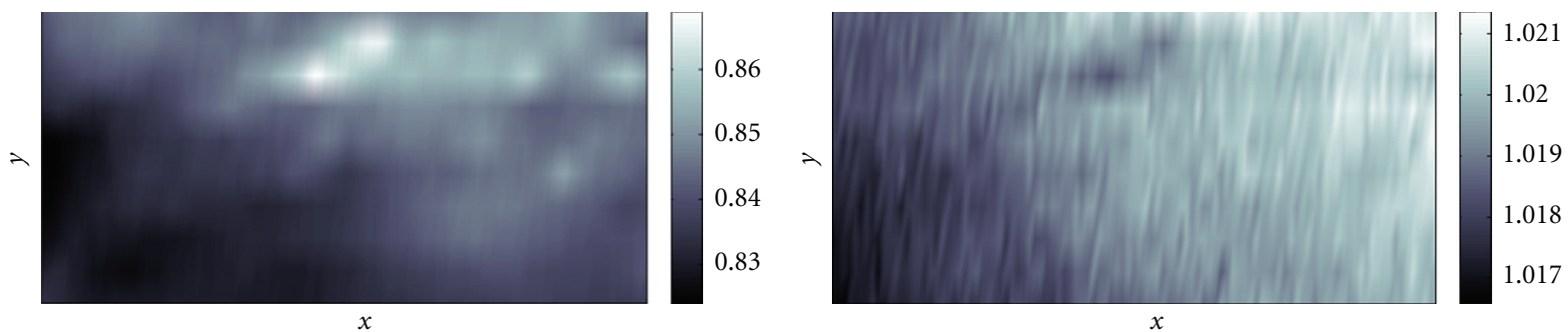

(b)
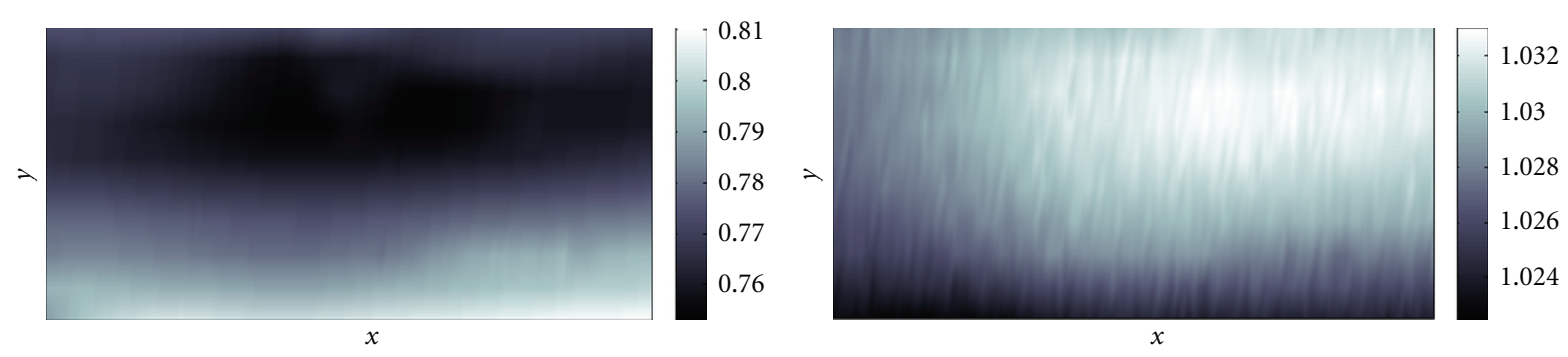

(c)
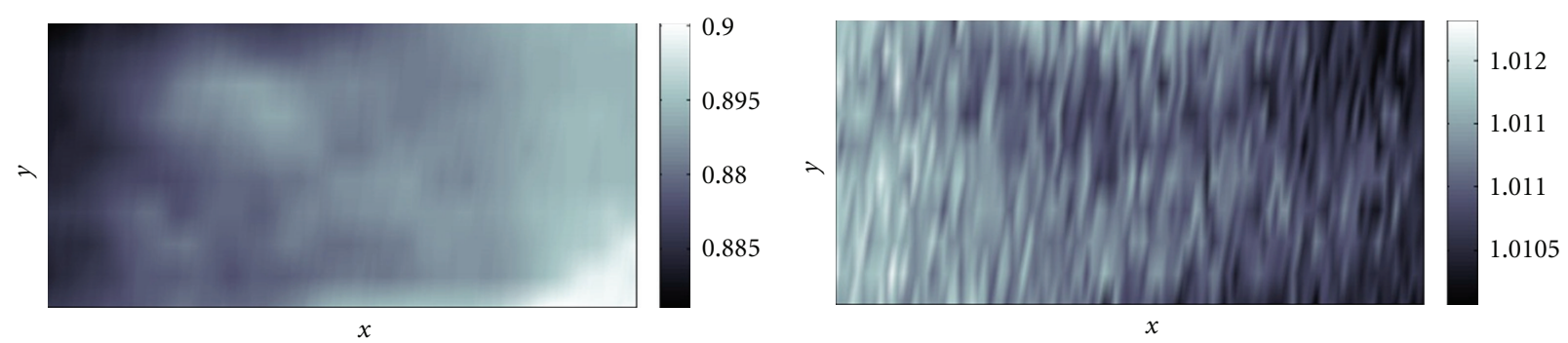

(d)
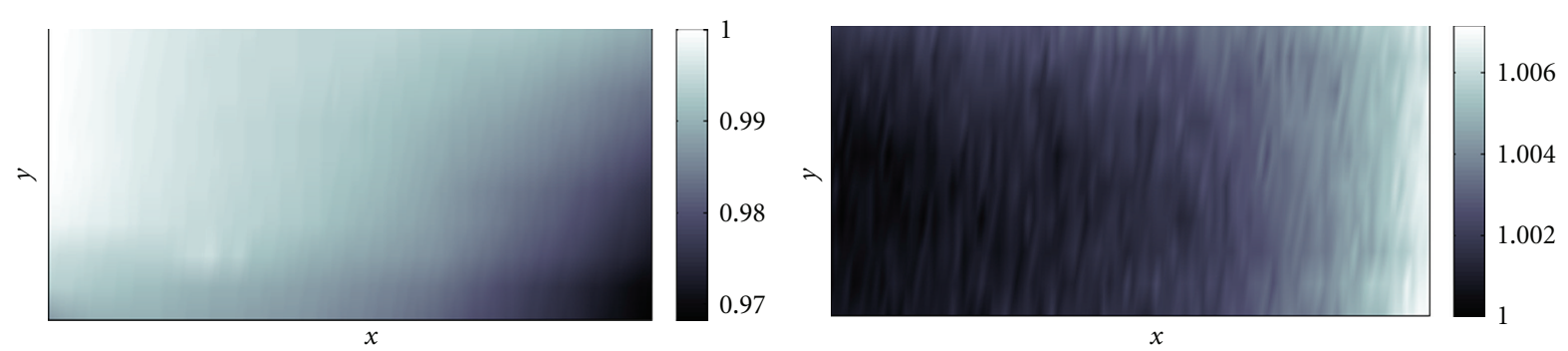

(e)

Figure 5: Results of two-dimensional scans obtained for samples: (a) S07 comprising of 0.7\% of $\sigma$ phase, (b) S19 comprising of 3.05\% of $\sigma$ phase, (c) S18 comprising of 3.2\% of $\sigma$ phase, (d) S02 comprising of $8.3 \%$ of $\sigma$ phase, and (e) S10 comprising of $15 \%$ of $\sigma$ phase. 


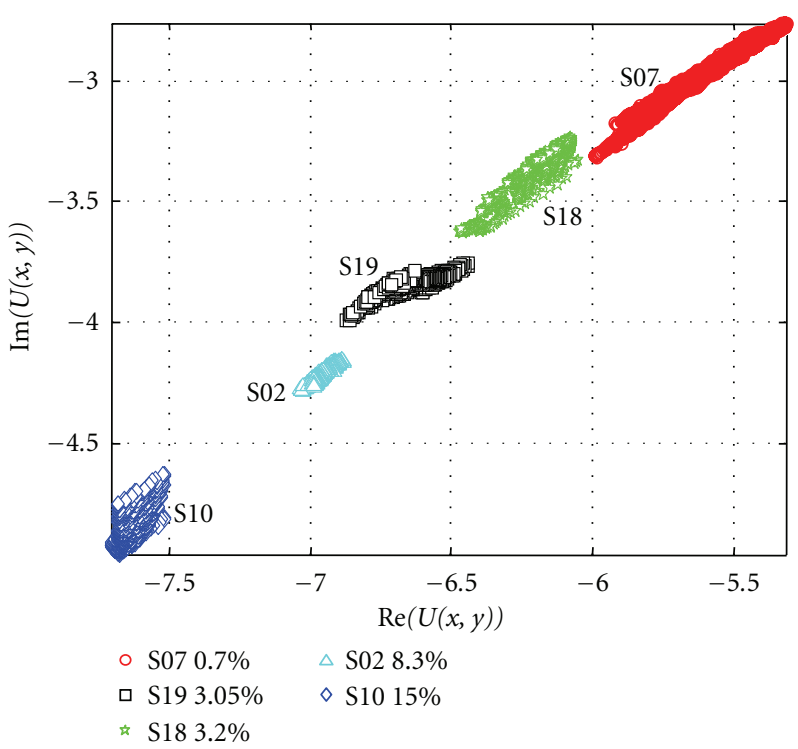

(a)

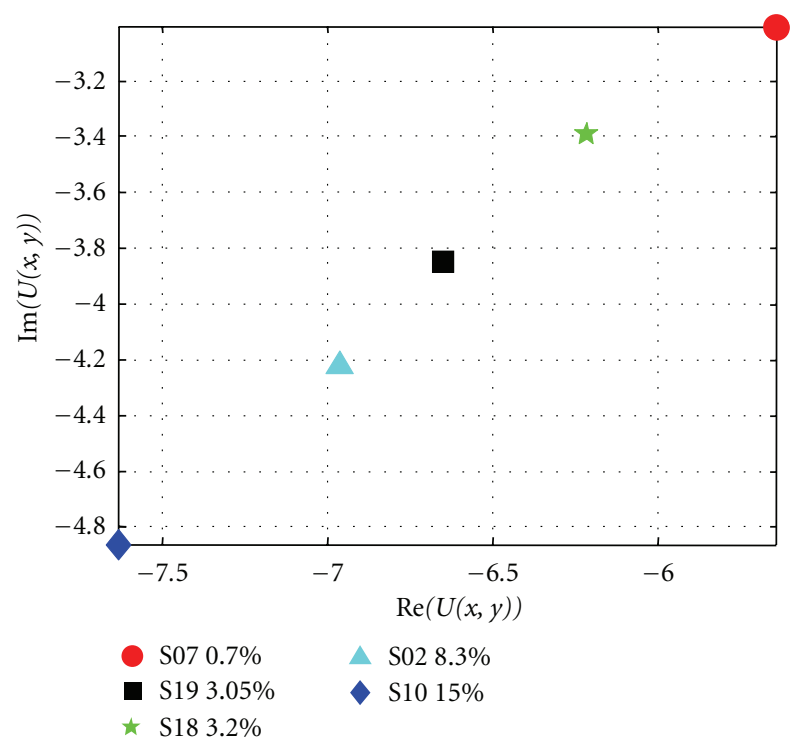

(b)

FIGURE 6: Results of two-dimensional scans obtained for samples comprising different amount of $\sigma$ phase presented in the complex plain: (a) distributions of measured signals in selected areas for each sample, (b) mean values of results presented in plot (a).

on measurements using testing frequency ranging from $1 \mathrm{kHz}$ up to $100 \mathrm{kHz}$. The main part of the system is a pick-up signal block where measured signal is extracted and amplified by a programmable lock-in amplifier. Signals generation and acquisition is carried out by multifunction data acquisition (DAQ) board. The DAQ device is controlled via USB interface by an embedded compact computer.

\section{Testing Samples}

Six DSS samples (specification UNS 31803) shown in Figure 4 were used to evaluate the proposed transducer. All samples were submitted to a preliminary solution heat treatment (Sol.) with the goal to obtain a balance of approximately $50 \%$ between both phases, ferrite $(\delta)$ and austenite $(\gamma)$. The solution heat treatment was conducted at $1120^{\circ} \mathrm{C}$ during one hour, followed by water quenching. Five samples received further aging heat treatments (Table 1) which introduced different amounts of sigma phase $(\sigma)$. The content of sigma phase was evaluated by utilizing scanning electron microscope (SEM) to different selected parts of the samples. To determine the amount of sigma phase, a small sample of DSS is placed into SEM. Fifty images are taken from different regions of the sample. Each image is processed using the commercial software ImagePro, and the phases are counted following the standard ASTM E1245-03. After the analysis of the 50 images, the mean and standard deviation value is extracted. One sample (S01) remained without aging and was used as a reference.

\section{Results of Measurements}

All samples were measured in the same way. The transducer was scanned over the sample's surface in two perpendicular directions over the area with dimensions $10 \times 30 \mathrm{~mm}$. Due to the large surface roughness, the transducer could not be in direct contact with the test sample, and lift-off had to be set. The impact of surface conditions on the results was verified using sample with only one side polished. Measured signal's parameters obtained for polished side with no lift-off and for unpolished side with lift-off of $0.5 \mathrm{~mm}$ were comparable, therefore further measurements were carried out for liftoff of $0.5 \mathrm{~mm}$. During the movement of the transducer, the output signal was measured. Two-dimensional distributions of the signals' amplitude and phase are shown in Figure 5. The 2-D plots illustrate spatial distribution of the material properties. One can observe that all the samples are not uniform, and the achieved results vary between measuring points. This can be explained by the fact that the contents of sigma phase vary in the tested area of samples, even taking upon consideration the areas of a few square $\mu \mathrm{m}$, which is much less than the dimensions of the transducer.

The scale of changes of the amount of sigma phase in samples was evaluated by the SEM technique. The standard deviation of the percentage of sigma phase obtained for different samples was reaching values even between $0.5 \%$ and $1 \%$. Considering this, proper evaluation and then drawing a distinction between samples comprising a similar amount of sigma phase can be hard to achieve. That is confirmed by the results obtained for S19 (3.05\%) and S18 (3.2\%). Therefore, in order to maximize the possibility of proper evaluation of sigma phase, the results achieved in all measured points were averaged for each sample. In order to compare results, common plots in a complex plane are provided (Figure 6). The distribution of the measured values presented in Figure 6(a) proves that the samples with different amount of the sigma phase $(\sigma)$ can be easily distinguished. The plot of averaged values (Figure 6(b)) shows that there is a linear 


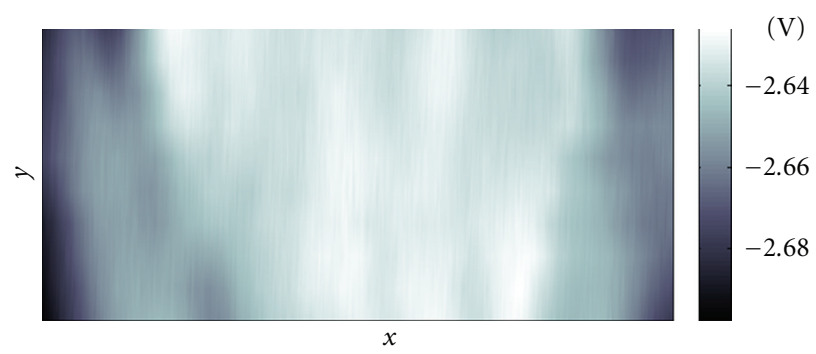

(a)

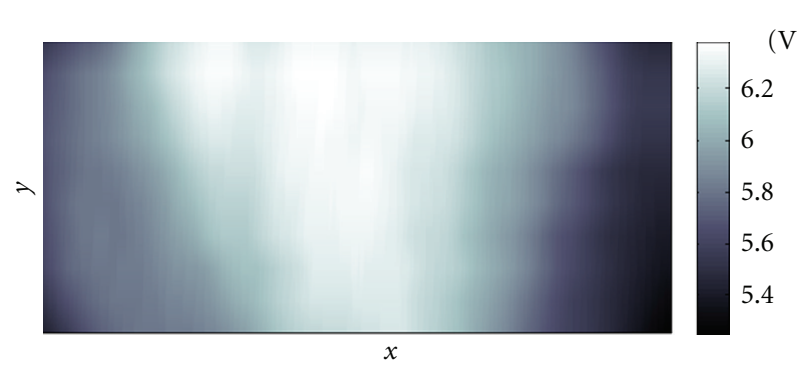

(b)

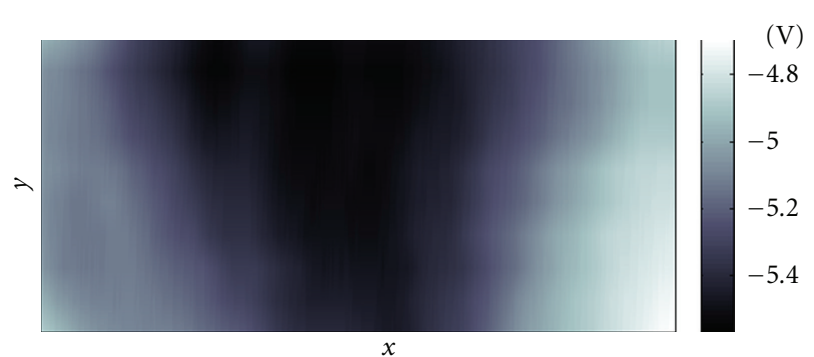

(c)

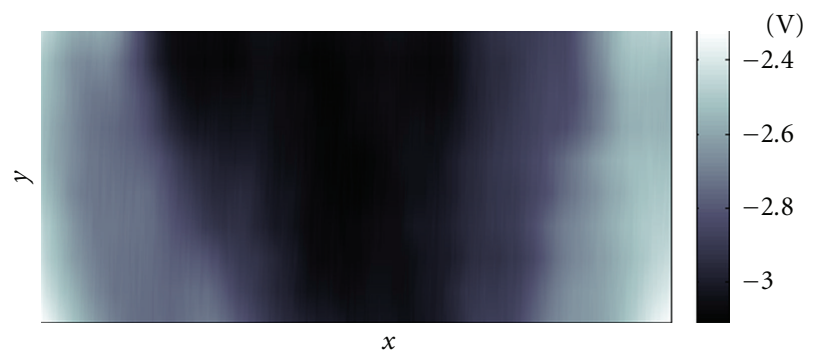

(d)

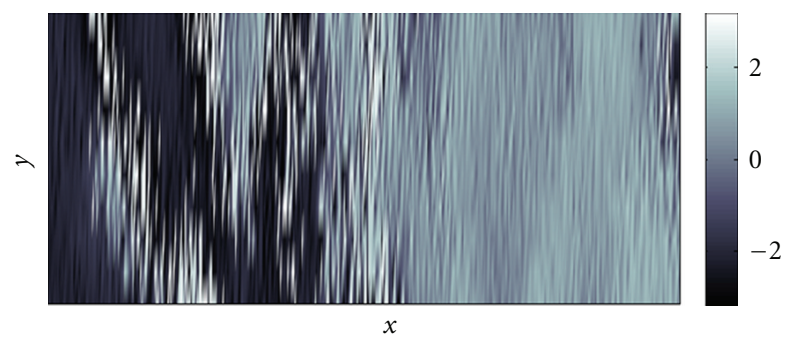

(e)

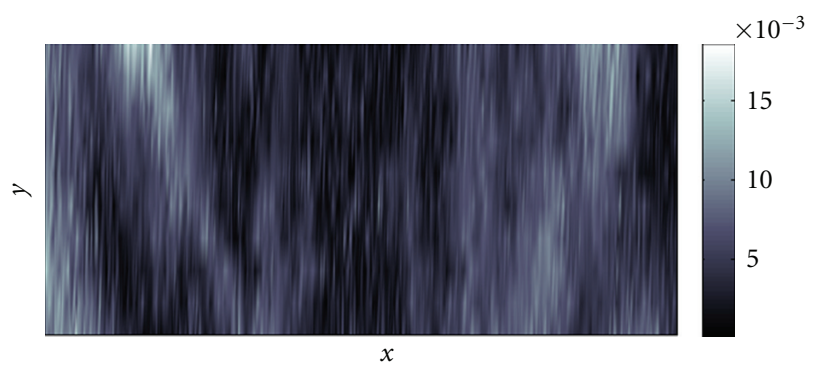

(f)

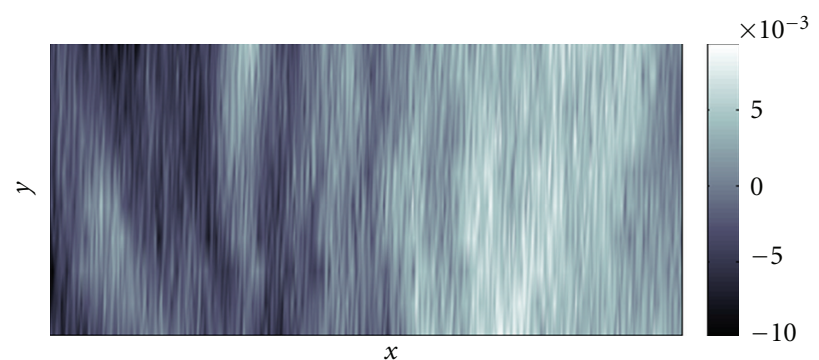

(g)

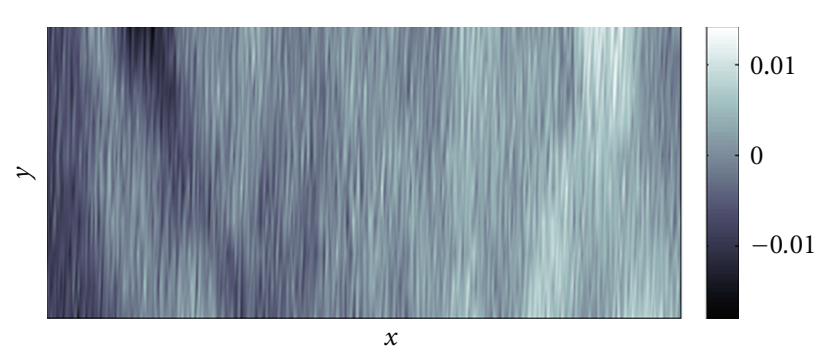

(h)

FIGURE 7: Results of two-dimensional scans obtained for sample with weld: (a) amplitude of measured signal $|U(x, y)|$, (b) phase of measured signal $\varphi(x, y)$, (c) real part of measured signal $\operatorname{Re}(U(x, y))$, (d) imaginary part of measured signal $\operatorname{Im}(U(x, y))$, (e) amplitude of gradient of measured signal $|\partial U(x, y) / \partial x|$, (f) phase of gradient of measured signal $\partial \varphi(x, y) / \partial x$, (g) real part of gradient of measured signal $\operatorname{Re}(\partial U(x, y) / \partial x)$, and (h) imaginary part of measured signal $\operatorname{Im}(\partial U(x, y) / \partial x)$.

TABle 1: List of samples.

\begin{tabular}{lccccc}
\hline Sample & Heat treatment & Temperature $\left[{ }^{\circ} \mathrm{C}\right]$ & $\begin{array}{c}\text { Time of treatment } \\
{[\mathrm{h}]}\end{array}$ & $\begin{array}{c}\text { Percentage of austenite } \\
{[\%]}\end{array}$ & $\begin{array}{c}\text { Percentage of Percentage of sigma } \\
\text { ferrite }[\%]\end{array}$ \\
\hline phase $[\%]$
\end{tabular}


dependence between the imaginary and real part of the measured signal in the case of different content of sigma phase $(\sigma)$. Similar relationship was observed in [7]. Some aspects of that relationship can be explained by the fact that sigma phase $(\sigma)$ is nonmagnetic, and if its amount is growing, material is getting less magnetic which results in lower coil inductance. However, the relationship between the phases and its impact on measured signal is not straightforward and has to be further investigated.

The performance of the method and the transducer was verified by utilizing DSS sample with a weld. The results of measurements obtained for selected area of the sample are presented in Figure 7. In order to emphasize the impact of changes of the material properties for measured signal, a gradient filtration in $x$ direction was carried out. One can observe that the changes of the material properties are clearly visible.

\section{Conclusions}

Presented results confirm that the proposed transducer and the whole system can be successfully used for evaluation of DSS and detection of sigma phase presence. The nearly linear dependence of the output signal on the amount of sigma phase creates opportunity of an adequate quantitative evaluation. Further works on the improvement of spatial resolution are necessary. High resolution is important especially in the case of the welds testing, where HAZ has a few $\mathrm{mm}$. It is also necessary to calibrate the system with bigger amount of samples in order to achieve better repeatability of the evaluation results.

\section{Acknowledgments}

This work was partly supported by European Commission Project (HEMOW) Health Monitoring of Offshore Wind Farms (ref.: FP7-PEOPLE-2010-IRSES-GA-269202). One of the authors would like to acknowledge the CNPq The Brazilian Council for Scientific and Technological Development, for a scholarship.

\section{References}

[1] W. Zhang, D. N. Zou, G. W. Fan, and J. Li, "Influence of aging time on sigma phase precipitation in SAF2507 super-duplex stainless steel," Materials Science Forum, vol. 620-622, pp. 355358, 2009.

[2] Y. Han, D. N. Zou, W. Zhang, J. H. Yu, and Y. Y. Qiao, "Influence of sigma phase precipitation on pitting corrosion of 2507 superduplex stainless steel," Materials Science Forum, vol. 658, pp. 380-383, 2010.

[3] J. M. A. Rebello, M. C. A. López, R. Sacramento, and K. S. De Assis, Quantification of Sigma Phase Precipitation by Magnetic Non Destructive Testing, Non-destructive Testing, Corrosion and Welding Laboratory, 2010.

[4] H. Sieurin and R. Sandström, "Sigma phase precipitation in duplex stainless steel 2205," Materials Science and Engineering A, vol. 444, no. 1-2, pp. 271-276, 2006.

[5] S. Topolska and J. Labanowski, "Effect of microstructure on impact toughness of duplex and superduplex stainless steels,"
Journal of Achievements in Materials and Manufacturing Engineering, vol. 36, no. 2, pp. 142-149, 2009.

[6] T. Chady, J. Kowalczyk, L. Nawos-Wysocki, G. Psuj, and I. Spychalski, "PLL based eddy current measuring system for inspection of outer flaws in titanium alloy plate," in Electromagnetic Nondestructive Evaluation (XIV), T. Chady, S. Gratkowski, T. Takagi, and S. S. Udpa, Eds., vol. 35, pp. 249-255, IOS Press, 2011.

[7] E. I. Todorov, M. G. Lozev, N. D. Ames, and L. O. Skogh, "Correlation between NDT measurements and sigma phase contents in duplex stainless steels," Review of Quantitative Nondestructive Evaluation, vol. 1096, pp. 1259-1266, 2009. 

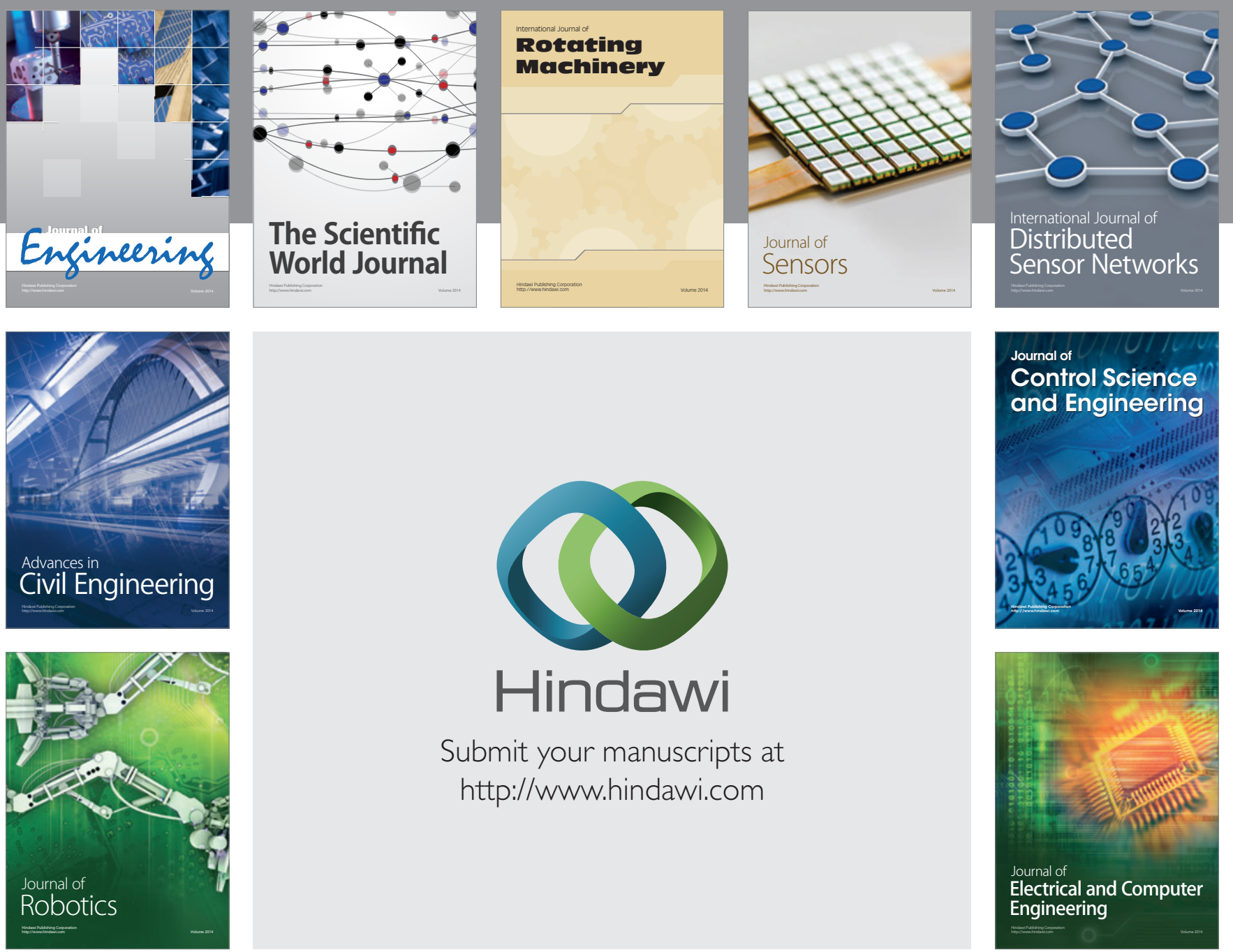

Submit your manuscripts at

http://www.hindawi.com
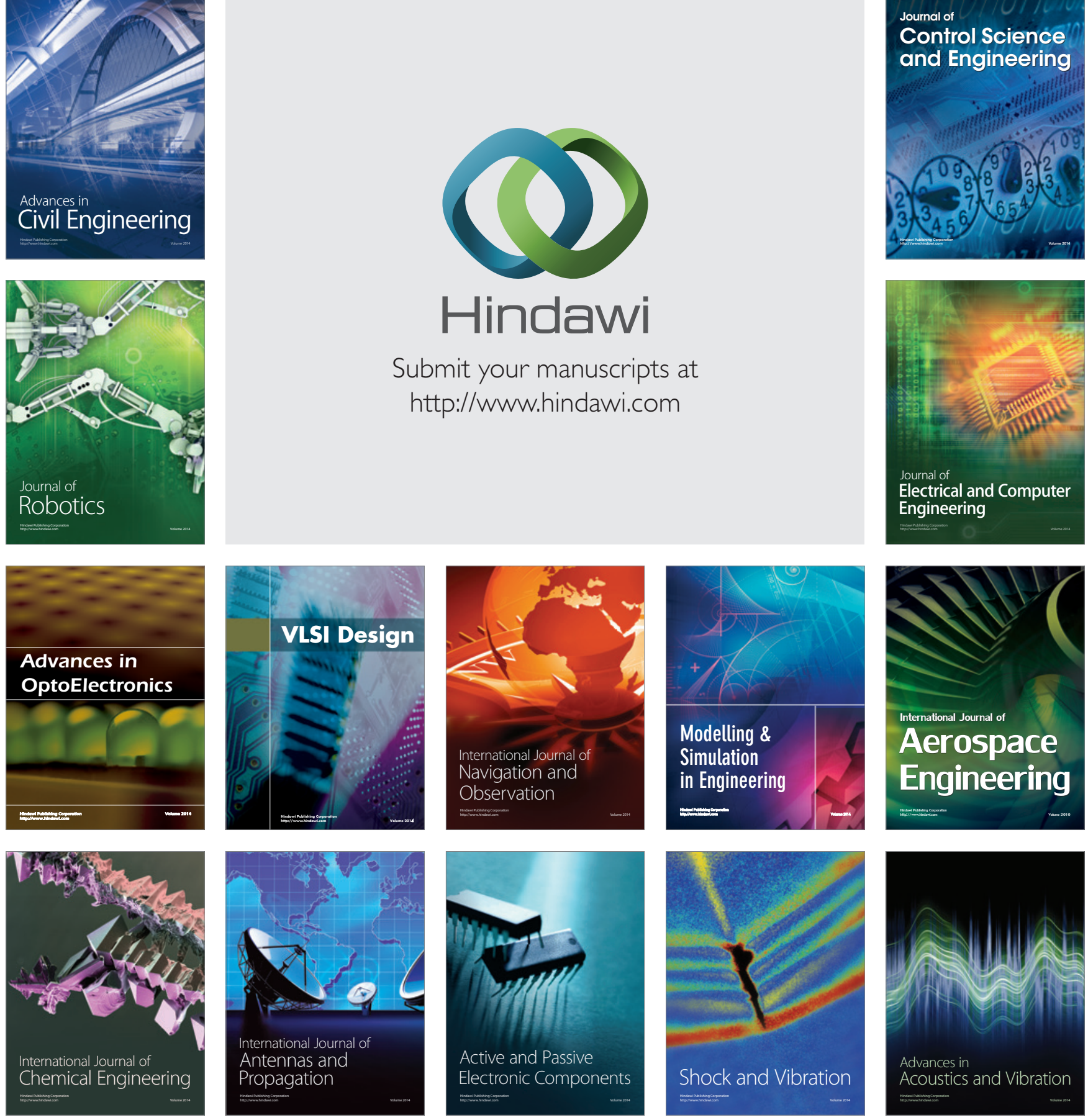